\title{
A CRITICAL REVIEW OF LEGAL ISSUES AND SOLUTIONS ASSOCIATED WITH BUILDING INFORMATION MODELLING
}

\author{
Su-Ling FAN ${ }^{1}$, Cen-Ying LEE $^{2}$, Heap-Yih CHONG $^{3}$, Mirosław J. SKIBNIEWSKI ${ }^{4}$ \\ ${ }^{1}$ Research Development Center of Construction Law, D204,5, Lane 199, \\ Kinghua Street, Taipei 10650, Taiwan \\ ${ }^{1}$ Department of Civil Engineering, Tamkang University, No. 151, Ying-Chuan Road, \\ Tamsui, Taipei County, Taiwan \\ ${ }^{2}$ Department of Construction Management, Curtin University, Australia \\ ${ }^{3}$ School of Built Environment, Curtin University, Australia \\ ${ }^{4}$ Department of Civil and Environmental Engineering, University of Maryland, College Park, USA
}

Received 13 February 2017; accepted 18 November 2017

\begin{abstract}
Although there are many discussions of the legal implications of BIM, none of the studies provides a comprehensive review of the legal issues associated with BIM; nor do they evaluate the solutions currently available to address the issues. This paper aims to provide a critical review of the legal issues arising from using BIM and of their associated solutions. A systematic review was conducted of fifty-five (55) journal articles and conference papers published from 2007 to 2017 to identify the legal issues. The identified legal issues were then analysed in relation to the solutions provided by the construction industry. The results of the study revealed that (1) an alternative project delivery approach that does not modify the original orientation of the design-bid-build procurement structure is required to deliver BIM effectively. (2) The potential change in the standard of care for project participants due to additional roles required in delivering BIM needs further investigation. (3) The roles for auditing a BIM delivery system must be included in the contracts to ensure the quality and compliance of BIM deliverables. The study not only reviews the legal issues associated with BIM, but more importantly, it also offers significant insights for future research.
\end{abstract}

Keywords: BIM, legal issues, contract, procurement, liability, risks.

JEL Classification: K12, O33, D83, D86, F68.

\section{Introduction}

Building information modelling (BIM) has become prominent as a significant element of operations in many construction projects (Ku \& Taiebat, 2011). It has proven one of the most effective computing tools for establishing and managing digital information over a project life cycle. However, BIM will not deliver significant improvement in existing procurement prac-

${ }^{\star}$ Corresponding author. E-mail: cenying.lee@postgrad.curtin.edu.au

This is an Open Access article distributed under the terms of the Creative Commons Attribution License (http://creativecommons. org/licenses/by/4.0/), which permits unrestricted use, distribution, and reproduction in any medium, provided the original author and source are credited. 
tices unless the issues surrounding its legal frameworks have been defined clearly and have been made more usable for procurement and contract management (Olatunji, 2014). The legal issues commonly discussed include incompatibility of procurement systems with BIM (Sebastian, 2011), liability of project participants arising due to design error, non-compliant design, translation error or data misuse, model ownership and intellectual property rights (IPR) (Arensman \& Ozbek, 2012) and unclear rights and responsibilities of project participants (Simonian \& Korman, 2010). To date, none of the conducted studies have compiled existing studies or comprehensively reviewed the legal issues discussed.

Thus, although the characteristics of BIM continue to evolve, many efforts have been made such as the development of standard contract protocols to address the legal concerns and the promotion of relational contracting approaches such as Integrated Project Delivery (IPD) to improve collaboration among project participants involved in BIM-enabled projects (Jones, 2014). However, none of the studies appraises how far these efforts have developed in addressing the legal issues. This gap in the current literature accelerates the need for a critical review on the legal issues associated with BIM to identify current developments in the construction industry to address the associated legal issues and discuss how current efforts could be improved.

This paper aims to critically review the legal issues arising from using BIM and their associated solutions. Through systematic reviews, fifty-five (55) journal articles and conference papers published from 2007 to 2017 were selected to identify the legal issues associated with BIM. Thereafter, each issue was critically reviewed using the existing documents such as journal articles, books and BIM contract protocols to discuss the current approaches to addressing the issues. Based on the results of the review, we then discussed future areas for research in the discussions and conclusions section.

\section{Review methodology}

To identify the legal issues arising from using BIM, a systematic review was conducted. This method was selected because it synthesises the research evidence by systematically adhering to guidelines for conducting the review (Grant \& Booth, 2009). The steps of systematic reviews were modified from Moher, Liberati, Tetzlaff, Altman, and Prisma Group (2009).

First, one of the authors identified the relevant papers via the Scopus database and Google Scholar. The keywords used to search the relevant academic publications were "legal issues BIM", "BIM legal", "BIM law" and "BIM contract".

Second, the downloaded papers were screened and checked for quality and eligibility to determine whether they discussed legal issues arising from using BIM. If the papers only briefly mentioned BIM's legal issues and did not elaborate details or types of legal issues, the papers were excluded. Thus, fifty-five (55) journal articles and conference papers that discussed the legal issues were selected for this study. Among the 55 papers, 27 papers were identified as journal articles. Figure 1 shows that the number of papers that discussed the legal issues from 2007 to 2017 increased unevenly, with the highest number (11) recorded in 2013. 


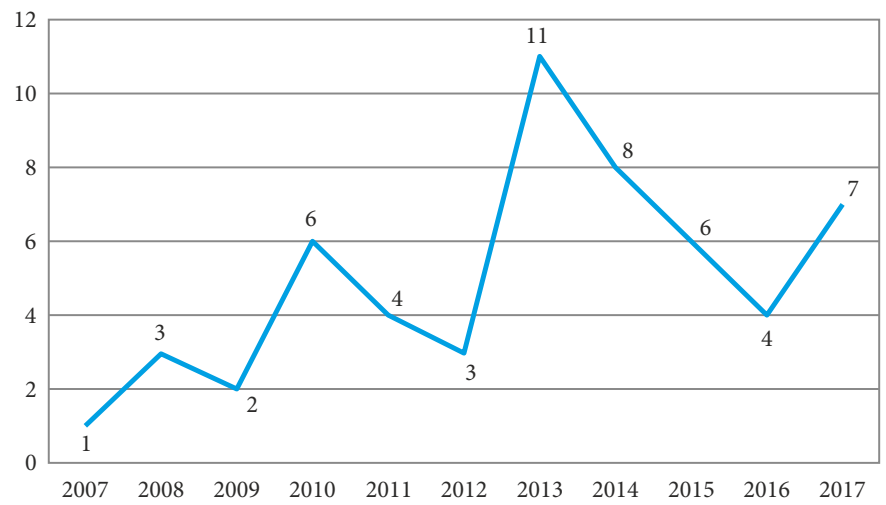

Figure 1. Papers published by year

Third, to prepare for the synthesis study, the legal issues discussed in the article were categorised according to the four common classifications as mentioned in the introduction, namely, (1) incompatibility of procurement systems with BIM, (2) liabilities arising from BIM use, (3) model ownership and IPR and (4) unclear rights and responsibilities. If the themes discussed in the articles were similar and formed the logic behind the theme, they were grouped into a similar theme within the four categories. However, if the legal issues discussed by the papers did not fit into the above four categories, a new main category of legal issues was created.

Additionally, the authors realised that legal issues and their solutions can vary across localities. For instance, the legal positions in the United States and the United Kingdom on the application of the economic loss doctrine are different. Hence, we decided to address the issues based on the two pioneer countries, namely, the legal application in the United States and in the United Kingdom. The similarities and the differences of the legal positions in these two countries also form parts of the central focus of the discussions.

There is no standard or guideline for a critical review of solutions because the aim of a critical review is to identify the most important items in the study and it requires not only the description but to include a certain level of analysis and innovation of concepts (Grant \& Booth, 2009). Hence, the authors searched the relevant literature to assess the current solutions. The common standard contract protocols from pioneer countries such as the AIA document E203TM-2013 (2013) and ConsensusDocs 301 (2008) from the United States and the CIC BIM Protocol (CIC, 2013a) and CIOB contract for use with complex projects (CCP, 2013) from the United Kingdom, published journal articles and relevant books were used in the discussions of the solutions.

After the reviewing process and the analysis were recorded, the content was then audited and validated by the other two authors, who were knowledgeable in BIM-based contract administration, to ensure the credibility of the systematic review. Finally, the findings were abstracted based on the aim identified in the Introduction, and the Discussions and Conclusions discussed the existing gaps and highlighted future research. 


\section{Findings of legal issues surrounding BIM}

Table 1 shows the results of findings obtained from fifty-five (55) academic publications. The legal issues were classified into four categories, namely, (1) incompatibility of procurement systems with BIM, (2) liabilities, (3) model ownership and IPR and (4) unclear rights and responsibilities.

Table 1. Legal issues identified from the papers

\begin{tabular}{|c|c|c|c|}
\hline No. & Legal Issues & References & $\begin{array}{l}\text { No. of } \\
\text { Papers }\end{array}$ \\
\hline 2.1 & $\begin{array}{l}\text { Incompatibility } \\
\text { of procurement } \\
\text { systems with BIM }\end{array}$ & $\begin{array}{l}\text { (Alreshidi, Mourshed, \& Rezgui, 2017); (Ashcraft, 2008); } \\
\text { (Chew \& Riley, 2013); (Eadie et al., 2013); (Gu \& London, } \\
\text { 2010); (Greenwood, Lewis, \& Lockley, 2010); (Ku \& Pollalis, } \\
\text { 2009); (Kuiper \& Holzer, 2013); (Liu, Van Nederveen, \& } \\
\text { Hertogh, 2017); (McAdam, 2010); (Olatunji, 2011); (Olatunji, } \\
\text { 2014); (Palos, Kiviniemi, \& Kuusisto, 2013); (Pandey, } \\
\text { Shahbodaghlou, \& Burger, 2016); (Sebastian, 2010); (Sebastian, } \\
\text { 2011) }\end{array}$ & 16 \\
\hline \multirow{4}{*}{2.1 .1} & $\begin{array}{l}\text { Design-bid-build } \\
\text { procurement } \\
\text { impedes effective } \\
\text { adoption of BIM }\end{array}$ & (Sebastian, 2011); (Pandey et al., 2016) & 2 \\
\hline & $\begin{array}{l}\text { More preparation } \\
\text { time to formulate } \\
\text { the collaboration } \\
\text { process is required }\end{array}$ & (Sebastian, 2011) & 1 \\
\hline & $\begin{array}{l}\text { Project } \\
\text { participants' } \\
\text { responsibilities to } \\
\text { work closely with } \\
\text { end users remained } \\
\text { limited }\end{array}$ & (Sebastian, 2011) & 1 \\
\hline & $\begin{array}{l}\text { Lack of early } \\
\text { involvement of } \\
\text { contractors }\end{array}$ & $\begin{array}{l}\text { (Elhag \& Al-Sharifi, 2014); (Palos et al., 2013); (Sebastian, } \\
\text { 2011) }\end{array}$ & 3 \\
\hline 2.1 .2 & $\begin{array}{l}\text { Lack of contract } \\
\text { forms to clearly } \\
\text { mandate the } \\
\text { BIM practices } \\
\text { and address legal } \\
\text { concerns }\end{array}$ & $\begin{array}{l}\text { (Abdirad, 2015); (Ahn, Kwak, \& Suk, 2015); (Alreshidi, } \\
\text { Mourshed, \& Rezgui, 2017); (Ashcraft, 2008); (Bataw, 2013); } \\
\text { (Bosch-Sijtsema, Isaksson, Lennartsson, \& Linderoth, 2017); } \\
\text { (Chao-Duivis, 2011); (Chong, Fan, Sutrisna, Hsieh, \& Tsai, } \\
\text { 2017); (Enegbuma, Ologbo, Aliagha, \& Ali, 2014); (Greenwood } \\
\text { et al., 2010); (Hamdi \& Leite, 2013); (Hsieh, Yeh, \& Hsu, } \\
\text { 2012); (Holzer, 2007); (Hossain, Munns, \& Rahman, 2013); } \\
\text { (Hsu, Hsieh, \& Chen, 2015); (Kuiper \& Holzer, 2013); (Kurul, } \\
\text { Abanda, Tah, \& Cheung, 2013); (Lowe \& Muncey, 2009); } \\
\text { (Manderson, Jefferies, \& Brwer, 2015); (McAdam, 2010); } \\
\text { (Mehran, 2016); (Ngo, 2012); (Olatunji, 2014); (Redmond, } \\
\text { Hore, \& West, 2010); (Sankaran et al., 2016); (Sebastian, 2010); } \\
\text { (Sun, Jiang, Skibniewski, Man, \& Shen, 2017); (Wang, Duan, \& } \\
\text { Lei, 2011) }\end{array}$ & 28 \\
\hline
\end{tabular}


Continue of Table 1

\begin{tabular}{|c|c|c|c|}
\hline No. & Legal Issues & References & $\begin{array}{l}\text { No. of } \\
\text { Papers }\end{array}$ \\
\hline \multirow{4}{*}{2.1 .2} & $\begin{array}{l}\text { The use of } \\
\text { "co-contract } \\
\text { document", } \\
\text { "inferential } \\
\text { document", } \\
\text { "geometry } \\
\text { statements", and } \\
\text { "reference only" } \\
\text { in the contract } \\
\text { documents }\end{array}$ & (Ashcraft, 2008); (Ku \& Pollalis, 2009); (Pandey et al., 2016) & 3 \\
\hline & $\begin{array}{l}\text { Conflicts in } \\
\text { terms between } \\
\text { protocols and } \\
\text { principal contract } \\
\text { if the standalone } \\
\text { amendment } \\
\text { contract is used }\end{array}$ & (Ghaffarianhoseini et al., 2017) & 1 \\
\hline & $\begin{array}{l}\text { Inaccurate, } \\
\text { insufficient and } \\
\text { inappropriate level } \\
\text { of BIM details } \\
\text { when delivering } \\
\text { models to owners }\end{array}$ & (Hamdi \& Leite, 2013) & 1 \\
\hline & Total & & 56 \\
\hline 2.2 & Liabilities & $\begin{array}{l}\text { (Ashcraft, 2008); (Chao-Duivis, 2011); (Joyce \& Houghton, } \\
\text { 2014); (Hossain et al., 2013); (Hsu et al., 2015); (Ku \& Pollalis, } \\
\text { 2009); (Kuiper \& Holzer, 2013); (Laishram, 2013); (Lowe \& } \\
\text { Muncey, 2009); (Mehran, 2016); (Sebastian, 2010); (Sebastian, } \\
\text { 2011); (Smith, 2014); (Wang et al., 2011) }\end{array}$ & 15 \\
\hline 2.2 .1 & $\begin{array}{l}\text { Liability exposures } \\
\text { to design errors, } \\
\text { non-compliant } \\
\text { design, transition } \\
\text { errors, loss of data } \\
\text { or data misuse }\end{array}$ & $\begin{array}{l}\text { (Abdirad, 2015); (Alreshidi et al., 2017); (Ashcraft, 2008); } \\
\text { (Azhar, Nadeem, Mok, \& Leung, 2008); (Bataw, 2013); (Chao- } \\
\text { Duivis, 2011); (Greenwood et al., 2010); (Ghaffarianhoseini } \\
\text { et al., 2017); (Hamdi \& Leite, 2013); (Hsieh et al., 2012); } \\
\text { (Hsu et al., 2015); (Kuiper \& Holzer, 2013); (Ku \& Pollalis, } \\
\text { 2009); (Laishram, 2013); (Lowe \& Muncey, 2009); (McAdam, } \\
\text { 2010); (Olatunji, 2011); (Olatunji, 2014); (Pandey et al., 2016); } \\
\text { (Sebastian, 2010); (Smith, 2014); (Walasek \& Barszez, 2017); } \\
\text { (Wang et al., 2011) }\end{array}$ & 23 \\
\hline 2.2 .2 & Standard of care & $\begin{array}{l}\text { (Arensman \& Ozbek, 2012); (Ashcraft, 2008); (Hsieh et al., } \\
\text { 2012); (Hsu et al., 2015); (Liu et al., 2017); (Lowe \& Muncey, } \\
\text { 2009); (McAdam, 2010); (Pandey et al., 2016); (Simonian \& } \\
\text { Korman, 2010) }\end{array}$ & 9 \\
\hline & Total & & 47 \\
\hline
\end{tabular}


Continue of Table 1

\begin{tabular}{|c|c|c|c|}
\hline No. & Legal Issues & References & $\begin{array}{l}\text { No. of } \\
\text { Papers }\end{array}$ \\
\hline 2.3 & $\begin{array}{l}\text { Model Ownership } \\
\text { and IPR }\end{array}$ & $\begin{array}{l}\text { (Abdirad, 2015); (Ahn et al., 2015); (Alreshidi et al., 2017); } \\
\text { (Al-Shammari, 2014); (Arensman \& Ozbek, 2012); (Ashcraft, } \\
\text { 2008); (Azhar et al., 2008); (Bataw, 2013); (Chao-Duivis, 2011); } \\
\text { (Davies et al., 2017); (Eadie, Odeyinka, Browne, McKeown, } \\
\text { Yohanis, 2014); (Elhag \& Al-Sahrifi, 2014); (Enegbuma \& } \\
\text { Ali, 2011); (Fan, 2014); (Greenwood et al., 2010); } \\
\text { (Ghaffarianhoseini et al., 2017); (Hossain et al., 2013); (Hsieh } \\
\text { et al., 2012); (Hsu et al., 2015); (Joyce \& Houghton, 2014); } \\
\text { (Ku \& Pollalis, 2009); (Kuiper \& Holzer, 2013); (Kurul et al., } \\
\text { 2013); (Laishram, 2013); (Lowe \& Muncey, 2009); (Mahamadu } \\
\text { et al., 2013); (Manderson et al., 2015); (McAdam, 2010); } \\
\text { (Mehran, 2016); (Ngo, 2012); (Olatunji, 2011); (Olatunji, } \\
\text { 2014); (Pandey et al., 2016); (Sebastian, 2010); (Simonian \& } \\
\text { Korman, 2010); (Smith, 2014); (Sun et al., 2017); (Walasek \& } \\
\text { Barszez, 2017) }\end{array}$ & 39 \\
\hline 2.3.1 & $\begin{array}{l}\text { Infringement of } \\
\text { Another's IPR }\end{array}$ & $\begin{array}{l}\text { (Elhag \& Al-Sharifi, 2014); (Fan, 2014); (Lowe \& Muncey, } \\
\text { 2009); (Pandey et al., 2016); (Rogers, Chong, \& Preece, 2015) }\end{array}$ & 5 \\
\hline 2.3 .2 & $\begin{array}{l}\text { How can business } \\
\text { knowledge be } \\
\text { protected? }\end{array}$ & (Chong et al., 2017); (Fan, 2014); (Pandey et al., 2016) & 3 \\
\hline 2.3 .3 & $\begin{array}{l}\text { Protection for } \\
\text { a creation that } \\
\text { requires hard work }\end{array}$ & (Fan, 2014); (Pandey et al., 2016) & 2 \\
\hline 2.3 .4 & $\begin{array}{l}\text { Security and Access } \\
\text { Control }\end{array}$ & $\begin{array}{l}\text { (Abdirad, 2015); (Alreshidi et al., 2017); (Azhar et al., 2008); } \\
\text { (Bataw, 2013); (Chong et al., 2017); (Eadie et. al., 2013); (Eadie } \\
\text { et al., 2014); (Ghaffarianhoseini et al., 2017); (Gu \& London, } \\
\text { 2010); (Hossain et al., 2013); (Joyce \& Houghton, 2014); } \\
\text { (Lowe \& Muncey, 2009); (Mahamadu, Mahdjoubi, \& Booth, } \\
\text { 2013); (Manderson et al., 2015); (Ngo, 2012); (Olatunji, 2011); } \\
\text { (Pandey et al., 2016); (Sun et al., 2017); (Yaakob, Wan, \& } \\
\text { Radzuan, 2016) }\end{array}$ & 19 \\
\hline & Total & & 68 \\
\hline 2.4 & $\begin{array}{l}\text { Unclear Rights and } \\
\text { Responsibilities }\end{array}$ & $\begin{array}{l}\text { (Alreshidi et al., 2017); (Chong et al., 2017); (Ghaffarianhoseini } \\
\text { et al., 2017); (Hamdi \& Leite, 2013) }\end{array}$ & 4 \\
\hline 2.4 .1 & Design delegation & $\begin{array}{l}\text { (Ashcraft, 2008); (Enegbuma \& Ali, 2011); (Pandey et al., } \\
\text { 2016); (Sebastian, 2010); (Simonian \& Korman, 2010) }\end{array}$ & 5 \\
\hline 2.4 .2 & $\begin{array}{l}\text { Roles involving } \\
\text { coordinating, } \\
\text { maintaining and } \\
\text { controlling the } \\
\text { model }\end{array}$ & $\begin{array}{l}\text { (Hamdi \& Leite, 2013); (Kurul et al., 2013); (Ku \& Pollalis, } \\
\text { 2009); (Liu et al., 2017); (Lowe \& Muncey, 2009); (Pandey et } \\
\text { al., 2016); (Sebastian, 2010); (Sebastian, 2011) }\end{array}$ & 8 \\
\hline 2.4 .3 & Auditing models & (Hamdi \& Leite, 2013) & 1 \\
\hline
\end{tabular}


End of Table 1

\begin{tabular}{|c|c|c|c|}
\hline No. & Legal Issues & References & $\begin{array}{l}\text { No. of } \\
\text { Papers }\end{array}$ \\
\hline 2.4 .4 & $\begin{array}{l}\text { Additional costs } \\
\text { arising from BIM } \\
\text { implementation }\end{array}$ & $\begin{array}{l}\text { (Arensman \& Ozbek, 2012); (Ashcraft, 2008); (Chao-Duivis, } \\
\text { 2011); (Elhag \& Al-Sharifi, 2014); (Holzer, 2007); (Hamdi \& } \\
\text { Leite, 2013); (Hossain et al., 2013); (Kurul et al., 2013); } \\
\text { (Manderson et al., 2015); (Mehran, 2016); (McAdam, 2010); } \\
\text { (Ngo, 2012); (Olatunji, 2011); (Olatunji, 2014); (Sebastian, } \\
\text { 2010); (Walasek \& Barszez, 2017) }\end{array}$ & 16 \\
\hline 2.4 .5 & $\begin{array}{l}\text { Rights of owners to } \\
\text { change the design }\end{array}$ & (Chao-Duivis, 2011) & 1 \\
\hline 2.4 .6 & $\begin{array}{l}\text { Privity of contract } \\
\text { and rights to rely } \\
\text { on the accuracy of } \\
\text { the models }\end{array}$ & $\begin{array}{l}\text { (Abdirad, 2015); (Al-Shammari, 2014); (Arensman \& Ozbek, } \\
\text { 2012); (Ashcraft, 2008); (Azhar et al., 2008); (Greenwood et al., } \\
\text { 2010); (Hsieh et al., 2012); (Joyce \& Houghton, 2014); (Ku \& } \\
\text { Pollalis, 2009); (Laishram, 2013); (Lowe \& Muncey, 2009); } \\
\text { (Manderson et al., 2015); (McAdam, 2010); (Olatunji, 2011); } \\
\text { (Simonian \& Korman, 2010) }\end{array}$ & 15 \\
\hline 2.4 .7 & $\begin{array}{l}\text { Avoidance of } \\
\text { responsibility } \\
\text { under means and } \\
\text { methods }\end{array}$ & $\begin{array}{l}\text { (Arensman \& Ozbek, 2012); (Ku \& Pollalis, 2009); (Laishram, } \\
\text { 2013); (Lowe \& Muncey, 2009) }\end{array}$ & 4 \\
\hline 2.4 .8 & Spearin Doctrine & $\begin{array}{l}\text { (Ashcraft, 2008); (Lowe \& Muncey, 2009); (Pandey et al., } \\
\text { 2016); (Simonian \& Korman, 2010); (Wang et al., 2011) }\end{array}$ & 5 \\
\hline & Total & & 59 \\
\hline
\end{tabular}

\subsection{Incompatibility of procurement systems with BIM}

How a facility is designed, built and maintained has evolved due to the attributes of BIM (Elmualim \& Gilder, 2013). BIM practices are said to collide with the design-bid-build professional responsibility principles (Ashcraft, 2008) because in this procurement system, the design responsibilities are assigned to a single entity such as the architect, structural engineer, or MEP engineer, whereas the contractor is in charge of construction. In a collaborative design, the model is no longer directed or supervised by any single entity. Responsibilities could be shared among the model contributors, which raises a critical question: can BIM still deliver its technical benefits without modifying the existing legal framework (Olatunji, 
2011)? Two main common legal issues arise when the design-bid-build method is used. First, the nature of the design-bid-build method is viewed as impeding the effective adoption of BIM (Sebastian, 2011). Second, there is a lack of contract forms that clearly mandate BIM practices and address legal concerns (Abdirad, 2015; Ashcraft, 2008; Bataw, 2013).

\subsubsection{Design-bid-build procurement impedes effective adoption of BIM}

There are two distinct viewpoints of the adoption of the design-bid-build method of delivering BIM. Ku and Pollalis (2009) study revealed that the line of responsibilities of project stakeholders (for example, each discipline creates its own derivative model) can still be maintained well in the design-bid-build procurement system (Ku \& Pollalis, 2009). However, another empirical study has shown that there a few limitations remain when adopting this method to deliver the full potential of BIM (Sebastian, 2011). Three main implications arise from these limitations:

\section{More preparation time to formulate the collaboration process is required}

To engage design-bid-build interdisciplinary teams for implementing BIM effectively, more preparation time was required to define common project goals, outline the collaboration process and formulate a semi-formal contract that specified the roles of project participants. Thus, even an architecture firm has an in-house structural engineering department to collaborate using the same software application selected to undertake the design. There is no guarantee that other project disciplines such as the MEP consultants and the contractors would be capable of using their own BIM tool to link directly with the BIM software used by the architecture and structural designer (Sebastian, 2011).

\section{Project participants' responsibilities to work closely with end users remained limited}

Even when the means of collaboration were defined at the beginning of the project, limited contractual responsibilities in the design-bid-build setting did not proactively engage project participants such as designers and contractors to work closely with the end user to address project lifecycle requirements (Sebastian, 2011).

\section{Lack of early involvement of contractors}

The design-bid-build system hinders early contractors' involvement. In the hospital projects that deployed the design-bid-build procurement method, the contractor's ICT system was only known after the tender stage. Particular attention was then given by the contractor to developing the object libraries (Sebastian, 2011).

\subsubsection{Lack of contract forms to clearly mandate the BIM practices and address legal concerns}

Traditional legal frameworks such as the design-bid-build method are used to accommodate fragmented conventions rather than to share contemporary contractual risks (Olatunji, 2011). Hence, there is a surge of alternative legal frameworks and contract documents to address the legal concerns and to define the roles of project participants.

The use of "co-contract document", "inferential document", "geometry statements", and "reference only" in the contract documents 
In an effort to incorporate BIM in contract documents, a question was also posted by the industry concerning whether the contracting parties can choose not to incorporate BIM into their contract documents. Typically, project participants can choose to use the model as a co-contract document (which governs the relationships between the parties), or they can use the model as an inferential document (which provides visualisation of the design intent inferable from the contract documents) and/or as an accommodation document (Pandey et al., 2016), such as the geometry statement or "reference only" documents. In the absence of a BIM contract protocol, project participants used BIM by only attaching geometry statement rules to describe the geometry requirements (Ashcraft, 2008). However, deployment of the geometry statement rules in a contract raises a critical issue. The geometry statement rules are not able to convey certain geometric complexities effectively. The best approach is to represent them in the digital model. When the complex geometry in a $3 \mathrm{D}$ model is maintained individually without residing in a central data repository, there is a high potential that a geometric discrepancy could occur (Ku \& Pollalis, 2009). Another approach is for the designer's CAD file to be used in support of the fabricator's proprietary CAD formats; this service is treated as "reference only" or "information purposes only". The designer's model remains the contract model. With this approach, the designer could warrant the accuracy of his model, but this approach of using the translated file exposes the fabricator to a significant liability (Ku \& Pollalis, 2009) that could affect the overall project collaboration. A recent survey performed by Pandey et al. (2016) indicated that one of the legal issues encountered was that majority of the designers were confused concerning the component parts of BIM that constitute a record of the contract. Hence, it is evident that potentially adverse consequences exist in project coordination if BIM is not included or is only "somewhat included" as part of a contract.

Conflicts in terms between protocols and principal contract if the standalone amendment contract is used

Some terms and conditions stated in the BIM protocol may conflict with the provisions in the main contract. For example, a more comprehensive of intellectual property licensing procedure is required in the BIM protocol as compared with that provided in the main construction contract (Ghaffarianhoseini et al., 2017). In case of disputes, the court may rule that the standard building contract which has an explicit term stated that priority shall be given to the terms in the main contract shall prevail over the Employer's Requirement (refer to legal case Fenice Investments Inc. (2009) EWHC 3272 (TCC)).

Inaccurate, insufficient and inappropriate level of BIM details when delivering models to owners

A significant benefit of using BIM is that the owner can use it for operating and maintaining the facilities. However, in reality, although the delivered models were contractually required by the owners, the owners still could not use the model due to (1) inappropriate detail for facility management needs, which was either more detailed than that provided by the contractor's model or incorporated insufficient details (particularly space and outside buildings) for owners to make strategic decisions; and/or (2) inaccuracy of the model delivered by the contractors because the contractors do not perceive the benefits of updating the model, although they are contractually required to do so (Hamdi \& Leite, 2013). 


\subsection{Liabilities}

In a BIM collaboration platform, project participants are typically required to share their design information through a common file format so that other project participants can integrate the data with their own data to create a federated BIM model. Liability arises when there is a requirement for information exchange among project participants. If the BIM information is transferable to be used by other parties, the designers are at a greater risk of exposure to professional liability (Haynes, 2009). Additionally, other project participants such as contractors are exposed to liability for file translation errors, loss of data or data misuse.

\subsubsection{Liability exposure to design errors, non-compliant design, transition errors, loss of data or data misuse}

It is necessary to determine whether liability or negligence becomes prominent in the contracts with respect to a duty to the employer, builder, designer or a third party (Kuiper \& Holzer, 2013). The most significant concern in this area is the liability of the designers' exposure for design error and non-compliant design. If the BIM-related software causes an error which results in economic loss to a designer, the designer's recovery is only restricted to the amount paid to the vendor for the software purchase (Pandey et al., 2016). This limitation does not cover the designer liability. Designers are exposed to greater risks due to design errors which caused by software imperfections can result in defects of the model or other deliverable items. Additionally, BIM has common functions to pre-load the data; these functions comply with local building regulations (McAdam, 2010). However, a liability issue can arise when the pre-loaded data are non-compliant. Other project participants including contractors and downstream contractors will also be exposed to greater liability in model sharing due to for example file transaction errors, loss of data or data misuse.

\subsubsection{Standard of care}

Liability for design is conventionally determined based on the "Standard of Care" for each discipline. "Standard of Care" is a law of tort which borrowed by contract law to identify the reciprocal responsibilities of contracting parties. The adoption of BIM gives rise to design issues such as what is the degree of collaboration can a designer have in a BIM working platform and still satisfy his professional standards? To what extent can he rely on other project participants' contributions and in the meantime satisfy this standard (Pandey et al., 2016)? Design and construction professionals are legally bound to a standard of care that requires them to perform with professional skill and care. PAS 1192-2 (2013) states that rendition of the native-format model file is used specially for spatial coordination processes. It is used to avoid clashes between models of building elements prepared by multidisciplinary teams. Presumably, if performing clash detection has become a standard BIM use by the designers in the BIM working platform, expectations of the reasonable skill and care of the designers in checking deviations will be higher than with previous practices. To illustrate further, in another example given by Hsieh et al. (2012), the standard of care can arise in the circumstance of BIM software imperfections. If the contract requires the project team members to review the output of the BIM software and discover any inconsistency or error produced by 
the software, the members would have a higher standard of care based on the rationale that the team members are capable of exercising their care in addressing the adverse ramifications caused by software imperfections. The use of BIM in the working platform of multidisciplinary teams can potentially change the standard of care of the project participants, which requires further investigation and future research.

\subsection{Model ownership and IPR}

Compared with other legal issues, the issues of model ownership and IPR were heavily discussed by a majority of the authors. The project participants' output must be shared with others through a common file format, giving rise to the issue of who should own the model and how should the IPR of the designers be protected. In an absence of contract language, the party who creates the model owns it (Larson \& Golden, 2007). It is also argued that the owners of the construction projects should own the native model and all of the exported data at the handover stage (Mordue, Swaddle, \& Philp, 2015). In a BIM platform, the issue of ownership also arises when each model contributor can potentially have ownership concerns with respect to their repurposing model and data (Arensman \& Ozbek, 2012). Bataw (2013) was of the view that the model should be legally retained by the client if the parties classify the BIM model as a product. Chao-Duivis (2011) asserted that the IPR is similar to a traditional collaboration. The model results from a joining of pieces of work from different parties, although the design appears to be unified. Therefore, the IPR of each element should be owned by its creator. The position of this legal issue is difficult to determine because there is no case law to establish a precedent (Eadie et al., 2014).

This issue is also noticeable in the empirical studies (Ku \& Pollalis, 2009). A portion of the architect's model belonged to the structural engineer's steel model. The model was shared to the contractor and other downstream subcontractors without including the fabricator and the subcontractors' derivative models. At the same time, the architect remained the owner of the principal geometry, and the detailed fabrication contributions in the model were controlled by the contractor. The model ownership and IPR issues become complicated because there are recurrent sharing of the models among project participants. This complication includes the issue of who shall be responsible for the defects of design and fabrication. Who ultimately owns the models that are part of the integrated work? In the illustrated case, should the model when in the midst of design, of fabrication, and of the final model stage belong to the structural engineer? Architect? Sheet-metal fabricator? Steelwork contractor? Or to the owner who paid for the work? These legal issues are very important from the perspectives of the authors of academic publications. In fact, protecting the BIM contributor's IPR is protecting their business interest against any competitor from using the contributor's ideas for their own profit without the contributor's consent. Another issue exists that pertains to intellectual property rights, which are commonly irrevocable or to licenses that can be suspended for non-payment. Hence, there is a high demand from the industry to define these issues in contracts if BIM is used. There are five legal implications identified that pertain to model ownership and IPR issues. 


\subsubsection{Infringement of another party's IPR}

The individual or organisation can generate profit by suing in instances of patent infringement when copyright is acquired (Lee et al., 2013). In the BIM working platform, the designers must share their design model with other project participants. Moreover, other project participants must use and access the model for the various purposes of the project. Hence, there is a potential for a party to claim infringement against other project participants based on the use of his copyright models (Fan, 2014).

\subsubsection{How can business knowledge be protected?}

In addition, in a BIM working platform, it is difficult to protect business knowledge. Designers are worried that the general contractors will use and modify their design model and sell it to the clients (Pandey et al., 2016). A BIM design model can consist of confidential trade information such as how a model of a manufacturing plant is planned to build and process. Hence, the question of how to protect business knowledge arises (Fan, 2014).

\subsubsection{Protection for a creation that requires hard work}

Another legal issue arises that is seldom discussed but is raised by Fan (2014) is, how does one protect his BIM element creations that require hard work? Most copyright acts indicate that only a unique expression can be protected. Despite the nature of BIM characteristics, an author could encounter an issue when registering a pattern and claiming copyright on BIM elements because he put a great deal of hard work into it.

\subsubsection{Security and access control}

The security issue is a hindrance to technology advancement. As the BIM becomes prominent and is stored in a central data repository that is shared with relevant project participants, the risk that data might be exposed to third parties or hackers or affected by viruses will increase. How well can the information be protected if the data are widely disseminated in a collaborative team (Ashcraft, 2008)?

\subsection{Unclear rights and responsibilities}

In a common data environment, the deployment of BIM to support multi-disciplinary information transfer has created new dimensions of the rights and responsibilities of project stakeholders in the construction industry (Kurul et al., 2013). Particularly in the design-bid-build procurement context, it is difficult to ensure that the designers will always be responsible for the creation and amendment of the digital model data (Simonian \& Korman, 2010). New roles such as a model manager are discovered and emerge. The model manager has the rights to coordinate the model elements and send and receive model data (Liu et al., 2017), but this point also raises the legal issue of how responsibilities are allocated among the designers, model managers, project managers and other relevant project participants. 


\subsubsection{Design delegation}

BIM is evolving, and it is a challenge for contract documents to keep pace with the new development of BIM. Nonetheless, the contract should address a few basic questions in connection with design delegation. For example, in the design-bid-build procurement system, does the architect remain the leading designer in the collaboration platform? Who shall be responsible for design quality? Who shall ensure that all deviations are resolved and that the model is reliable? How are the responsibilities and input-output workflows of project participants determined if they are involved simultaneously in the process (Sebastian, 2010)? For BIM uses such as automatically detecting changes in the other disciplines and responses to the owned design software, none of the designers checked the information before it is incorporated into the model. In such a case, should the standards committees who create the BIM protocols be "the designer"? What are the responsibilities of another designer? The coordination function of the contracts is to outline the roles and responsibilities of the parties involved in BIM projects to enable them to coordinate the relationship formally. Appropriate limitations of liability and waivers should be considered when developing contract documents (Ashcraft, 2008).

\subsubsection{Roles involving coordinating and maintaining the model}

One of the design delegation issues that are commonly discussed is the role of a model manager. There is no doubt that a model manager will be useful to support greater coordination for developing an integrated model (Gu, Singh, London, Brankovic, \& Taylor, 2008). However, lack of clarity in the responsibilities of a model manager might impede the full advantage of this role (Liu et al., 2017). The implications were observed in two hospital projects studied by Sebastian (2011). An independent model manager had been appointed in one of the hospitals, whereas the other hospital appointed the architect to commit the role of the model manager. The model manager in the former hospital was responsible for consolidating and coordinating all models for clear information exchange. However, this task was not common for the architect in the latter hospital. To perform the tasks of the model manager, ICT knowledge is required to handle the information. This requirement undoubtedly raised an issue concerning the division of roles among the designer, project manager and model manager. It also has implications for designers such as architects who must cope with the BIM ICT system so that they are capable of maintaining their creativity and conducting the design processes.

\subsubsection{Auditing models}

Auditing models is a significant issue. Although BIM simulation software is capable to audit the database fields, there is still a lack of building-code-review compliance analysis. Consequently, no design is executed until construction permits are issued and have met all requirements (Hamdi \& Leite, 2013). Additionally, standard protocols stipulate the responsibility of the model contributor to ensure model integrity (ConsensusDocs 301, 2008; CCP, 2013). However, it is not necessary that a party such as a Contractor comply with the requirements of model deliverables when the project is completed, because there is no provision in the contracts mentioning the consequences and the liabilities of non-compliance. Nor do the 
contracts define the penalty for non-compliance of the model. Hence, the roles of auditing models to ensure compliance with not only building codes but also employer requirements become significant.

\subsubsection{Additional costs arising from BIM implementation}

A certain level of investment is required to implement BIM. The costs include those of purchasing the software and hardware associated with BIM, management and operation costs, the cost of appointing a model manager and any other associated costs. A legal question that arises is, who shall be responsible for the extra cost? If the project owner requires the team members to use BIM, shall he bear the cost of appointing the model manager? Additionally, whether the project participants are compensated for the additional cost of BIM remains undetermined (Arensman \& Ozbek, 2012).

\subsubsection{Rights of owners to change the design}

Another important legal issue is, what rights does the employer receive when the model is delivered to him? A client has the right to realise the design using BIM. However, a more critical question is, does he have the right to alter the design that used BIM? If he has that right, does it mean that he has an exclusive right to alter the BIM design before and during construction (Chao-Duivis, 2011)?

\subsubsection{Privity of contract and rights to rely on}

In risk allocation, one of the main legal concerns is "privity of contract". The issue of "privity of contract" applies to both the United States and the United Kingdom. The "privity of contract" rules indicate that rights or obligations on anyone can only be granted or imposed on the parties who are involved in the contract (Hsieh et al., 2012). The project team members' ability to access the shared model gives rise to the right to rely on the contributions of other members. Therefore, is privity an issue? In the presence of this principle, downstream project participants such as the contractor or subcontractor in the traditional procurement who used to rely on the designers' model might not have the right to file an action against the designer for economic loss resulted from negligent errors because there is no contract bond between the contractors or subcontractors and the designers (Ashcraft, 2008). Moreover, whether the employer can rely on the accuracy of the models provided by the project participants is another issue. In the BIM platform, the owners must rely on not only the designer's model but also the information model for other uses such as the model used for quantity take-off and facility management.

\subsubsection{Avoidance of responsibility under means and methods}

In the United States, one of the core principles governs the design-bid-build contracts is that when a contractor is paid to build in accordance with plans and specifications provided by the employer, the contractor is in charge of his means and methods unless the plans and specifications stated a particular means or method. In the empirical studies examined by $\mathrm{Ku}$ and Pollalis (2009), a fabricator of metal cladding was appointed to provide design advice during the design and construction phases. A proprietary prefabrication of a cladding system 
was included to define the building skin geometry, whereas the architect was responsible for creating a design model. Hence, there is a greater risk exposed to the employer pertaining to damages if there is a design defect in the cladding system, but the fabricator was found to have no liability for the defect because he controls the means and methods of the cladding system based on the geometry statement supplied by the designer.

\subsubsection{Spearin doctrine}

In the United States, the Spearin doctrine protects a contractor against a client's assertion of faulty and noncompliant work (Simonian \& Korman, 2010). The Spearin doctrine ruled that it is adequate for a client's intended purpose if he impliedly warrants the information to the contractor. In case of a defect, Spearin shifts the responsibility to the employer's design team (Foster, 2008). The contractor is not liable if he constructs in accordance with the employer's BIM model. However, note that this principle does not apply if the contractor contributed relevant information in designing a facility. The Spearin doctrine is contrasted with the legal position in the United Kingdom, in which the common law is more willing to assign the risk to the contractor (McAdam, 2010).

\section{Associated solutions}

Table 2 shows the solutions associated with the legal issues identified from the standard protocols, guidelines, journals and other relevant references.

Table 2. Associated solutions to legal issues

\begin{tabular}{|c|c|c|c|}
\hline No. & Legal Issues & Associated Solutions & References \\
\hline 3.1 & $\begin{array}{l}\text { Incompatibility of } \\
\text { procurement systems with } \\
\text { BIM }\end{array}$ & & \\
\hline 3.1 .1 & $\begin{array}{l}\text { Lack of contract forms to } \\
\text { clearly mandate the BIM } \\
\text { practices and address legal } \\
\text { concerns }\end{array}$ & $\begin{array}{l}\text { Amendments to existing } \\
\text { contracts }\end{array}$ & $\begin{array}{l}\text { (AIA E203TM-2013, 2013); } \\
\text { (ConsensusDocs 301, 2008); } \\
\text { (CIC, 2013a); (CCP, 2013); } \\
\text { (Udom, 2013); (Sebastian, 2011) }\end{array}$ \\
\hline 3.1 .2 & $\begin{array}{l}\text { Design-bid-build } \\
\text { procurement impedes } \\
\text { effective adoption of BIM }\end{array}$ & $\begin{array}{l}\text { Adoption of relational } \\
\text { project delivery systems }\end{array}$ & $\begin{array}{l}\text { (ACIF, 2014); (AIA Doc. C191, } \\
\text { 2009); (ConsensusDOCS 300, } \\
\text { 2007); (Lahdenperä, 2012); } \\
\text { (PPC 2000, 2000) }\end{array}$ \\
\hline 3.1 .3 & $\begin{array}{l}\begin{array}{l}\text { Design-bid-build } \\
\text { procurement impedes } \\
\text { effective adoption of BIM }\end{array} \\
\end{array}$ & $\begin{array}{l}\text { Early contractor } \\
\text { involvement }\end{array}$ & (Palos et al., 2013) \\
\hline 3.2 & Liabilities & & \\
\hline 3.2 .1 & $\begin{array}{l}\text { Liability exposures to } \\
\text { design errors, non- } \\
\text { compliant design, } \\
\text { transition errors, loss of } \\
\text { data or data misuse/ } \\
\text { Standard of care }\end{array}$ & $\begin{array}{l}\text { Principles of economic } \\
\text { loss doctrine and } \\
\text { common law }\end{array}$ & $\begin{array}{l}\text { (Ashcraft, 2008); (Simonian \& } \\
\text { Korman, 2010); (McAdam, } \\
\text { 2010) }\end{array}$ \\
\hline
\end{tabular}


Continue of Table 2

\begin{tabular}{|c|c|c|c|}
\hline No. & Legal Issues & Associated Solutions & References \\
\hline 3.2 .2 & $\begin{array}{l}\text { Liability exposures to } \\
\text { design errors, non- } \\
\text { compliant design, } \\
\text { transition errors, loss of } \\
\text { data or data misuse }\end{array}$ & Addressed by contracts & $\begin{array}{l}\text { (ConsensusDocs 301, 2008); } \\
\text { (CIC, 2013a); (CCP, 2013); } \\
\text { (Udom, 2013) }\end{array}$ \\
\hline 3.2 .3 & $\begin{array}{l}\text { Liability exposures to } \\
\text { design errors, non- } \\
\text { compliant design, } \\
\text { transition errors, loss of } \\
\text { data or data misuse }\end{array}$ & $\begin{array}{l}\text { Professional Indemnity } \\
\text { Insurance }\end{array}$ & $\begin{array}{l}\text { (Ashcraft, 2008); (Bataw, 2013); } \\
\text { (ConsensusDocs 301, 2008); } \\
\text { (CIC, 2013b); (CCP, 2013); } \\
\text { (Eadie et al., 2014) }\end{array}$ \\
\hline 3.3 & Model Ownership and IPR & & \\
\hline 3.3 .1 & Model ownership and IPR & Addressed by contracts & $\begin{array}{l}\text { (AIA E203TM-2013, 2013); } \\
\text { (CIC, 2013a); (ConsensusDocs } \\
\text { 301, 2008); (CCP, 2013) }\end{array}$ \\
\hline 3.3 .2 & $\begin{array}{l}\text { Infringement of Another's } \\
\text { IPR }\end{array}$ & Addressed by contracts & $\begin{array}{l}\text { (AIA E203TM-2013, 2013); } \\
\text { (CIC, 2013a); (ConsensusDocs } \\
\text { 301, 2008); (CCP, 2013) }\end{array}$ \\
\hline 3.3 .3 & $\begin{array}{l}\text { Protection of Business } \\
\text { Knowledge }\end{array}$ & Addressed by contracts & $\begin{array}{l}\text { (AIA E203TM-2013, 2013); } \\
\text { (CIC, 2013a); (ConsensusDocs } \\
\text { 301, 2008) }\end{array}$ \\
\hline 3.3 .4 & $\begin{array}{l}\text { Protection for a creation } \\
\text { that requires hard work }\end{array}$ & $\begin{array}{l}\text { Set up a coding system } \\
\text { of parameters or } \\
\text { information structure of } \\
\text { all BIM elements }\end{array}$ & (Fan, 2014) \\
\hline 3.3 .5 & $\begin{array}{l}\text { Security and Access } \\
\text { Control }\end{array}$ & Addressed by contracts & $\begin{array}{l}\text { (AIA E203TM-2013, 2013); } \\
\text { (CIC, 2013a); (ConsensusDocs } \\
\text { 301, 2008); (CCP, 2013) }\end{array}$ \\
\hline 3.4 & $\begin{array}{l}\text { Unclear Rights and } \\
\text { Responsibilities }\end{array}$ & & \\
\hline 3.4 .1 & Design Delegations & $\begin{array}{l}\text { Addressed by contracts } \\
\text { and standard guidelines }\end{array}$ & $\begin{array}{l}\text { (CIC, 2013a); (ConsensusDocs } \\
\text { 301, 2008); (CCP, 2013); } \\
\text { (PAS1192-2, 2013) }\end{array}$ \\
\hline 3.4 .2 & $\begin{array}{l}\text { Roles of Coordinating and } \\
\text { Maintaining Model }\end{array}$ & Addressed by contracts & $\begin{array}{l}\text { (CIC, 2013a); (ConsensusDocs } \\
\text { 301, 2008); (CCP, 2013) }\end{array}$ \\
\hline 3.4 .3 & Auditing models & Addressed by contracts & $\begin{array}{l}\text { (CIC, 2013a); (CCP, 2013); } \\
\text { (Hamdi \& Leite, 2013) }\end{array}$ \\
\hline 3.4 .4 & $\begin{array}{l}\text { Additional costs arising } \\
\text { from BIM implementation }\end{array}$ & $\begin{array}{l}\text { (a) Addendum to } \\
\text { professional scales of } \\
\text { fees is required. } \\
\text { (b) Additional payment } \\
\text { to designers is not } \\
\text { required if using } \\
\text { BIM makes the } \\
\text { design process more } \\
\text { efficient. } \\
\text { (c) Employer should } \\
\text { responsible to } \\
\text { appoint the model } \\
\text { manager }\end{array}$ & $\begin{array}{l}\text { (Olatunji, 2011) } \\
\text { (Arensman \& Ozbek, 2012) } \\
\text { (CCP, 2013); (CIC, 2013a); } \\
\text { (ConsensusDocs 301, 2008) }\end{array}$ \\
\hline
\end{tabular}


Continue of Table 2

\begin{tabular}{|c|c|c|c|}
\hline No. & Legal Issues & Associated Solutions & References \\
\hline 3.4 .5 & $\begin{array}{l}\text { Rights of owners to change } \\
\text { the design }\end{array}$ & $\begin{array}{l}\text { The owner may or may } \\
\text { not grant the license } \\
\text { to change the design } \\
\text { which is subject to the } \\
\text { agreement. }\end{array}$ & (Chao-Duivis, 2011) \\
\hline 3.4 .6 & $\begin{array}{l}\text { Privity of contract and } \\
\text { rights to rely on the } \\
\text { accuracy of the models }\end{array}$ & $\begin{array}{l}\text { Privity of contract } \\
\text { (a) In the US. } \\
\text { Restatement of Torts } \\
\text { (Second) Section } \\
552 \text { allows non- } \\
\text { contractual parties } \\
\text { claim damages } \\
\text { against the other } \\
\text { party who is aware } \\
\text { that the party rely on } \\
\text { the accuracy of its } \\
\text { model. } \\
\text { (b) Also addressed } \\
\text { explicitly by } \\
\text { contracts. } \\
\text { (c) In the UK, the } \\
\text { existence of tortious } \\
\text { liability for pure } \\
\text { economic loss } \\
\text { depends on the } \\
\text { precise factual } \\
\text { nature of the } \\
\text { relationship between } \\
\text { the parties instead of } \\
\text { its designation. } \\
\text { Rights to rely on the } \\
\text { accuracy of model } \\
\text { (a) Parties have rights to } \\
\text { rely on the accuracy } \\
\text { of the model which } \\
\text { are stated in the } \\
\text { contracts. } \\
\text { (b) Contractor may rely } \\
\text { on the information } \\
\text { provided by the } \\
\text { Owner which } \\
\text { depends on the } \\
\text { status identified } \\
\text { in the Special } \\
\text { Conditions. } \\
\text { (a) }\end{array}$ & \begin{tabular}{|l|} 
(Ashcraft, 2008) \\
(ConsensusDocs 301, 2008) \\
(McAdam, 2010) \\
(AIA E203TM-2013, 2013); \\
(ConsensusDocs 301, 2008); \\
(CCP, 2013)
\end{tabular} \\
\hline 3.4 .7 & $\begin{array}{l}\text { Avoidance of responsibility } \\
\text { under means and methods }\end{array}$ & $\begin{array}{l}\text { Only applicable in the } \\
\text { US. Deploy contracts } \\
\text { to prevent any liability } \\
\text { for construction } \\
\text { means, methods, } \\
\text { techniques, sequences, } \\
\text { or procedures. }\end{array}$ & (Ku \& Pollalis, 2009) \\
\hline
\end{tabular}


End of Table 2

\begin{tabular}{|c|l|l|l|}
\hline No. & \multicolumn{1}{|c|}{ Legal Issues } & \multicolumn{1}{|c|}{ Associated Solutions } & \multicolumn{1}{c|}{ References } \\
\hline & Spearin Doctrine & $\begin{array}{l}\text { Only applicable in the } \\
\text { US. Addressed explicitly } \\
\text { by the Addendum } \\
\text { that it is not intended } \\
\text { to restructuring } \\
\text { contractual relationship. }\end{array}$ & \\
& & $\begin{array}{l}\text { (ConsensusDocs 301, 2008); } \\
\text { (Lence, the traditional } \\
\text { responsibilities and risk } \\
\text { allocation of the parties } \\
\text { alill remain. }\end{array}$ & \\
& & & \\
\hline
\end{tabular}

\subsection{Incompatibility of procurement systems with BIM}

In addressing the legal issues discussed above, three alternative approaches were adopted by the construction industry: (1) amendments to existing contracts, (2) adoption of relational project delivery systems and (3) early contractor involvement.

\subsubsection{Amendments to existing contracts}

Amendment to the existing contracts without altering the original orientation of the designbid-build framework is perhaps the most plausible solution in the eyes of most of the project stakeholders because they can still deliver the BIM at the same time, maintaining their conventional lines of responsibilities with a minimum adjustment of their current roles. However, the question to resolve beforehand is whether project stakeholders should develop a principal contract directly by including the BIM related provisions such as the approach adopted by CIOB contract for complex projects (CCP, 2013), or should they develop a standalone amendment contract such as ConsensusDocs 301 (2008), CIC BIM Protocol (CIC, 2013a) or AIA Document E203TM-2013 (2013). If a standalone amendment contract is required, a statement that mentions the priority of the BIM protocol over other contract documents should be included to prevent an unwanted dispute as mentioned previously. Additionally, elements such as provisions of waivers, indemnities, and liability for contribution should be included in the contract to make it appropriate as a stand-alone amendment (Udom, 2013).

Moreover, it is suggested that the owner and his consultants should define the requirements of the type of BIM software used in the tender documents to avoid requiring additional effort by contractors and fabricators to translate the files at a later stage of the project. Additionally, the owner should set out detailed requirements for model deliverables for his use during the facility operation, emphasise the importance of the deliverables and appoint consultants or a third party to verify the models to overcome cultural pitfalls, for example, contractors not following the model deliverable requirements. Prior to BIM implementation, the agreements which project participants must achieve at minimum include the desired modelling approach, the degree of detail of models, and any supporting tools that are required to resolve the complexity of the project and achieve the project objectives by the project participants (Sebastian, 2011). AIA E203TM-2013 (2013) specified that the services of providing a post-construction model shall only be required if a table that defines the 
types of post-construction model uses, the responsibility of project participants to create or adapt the model to acquire the uses and the location of detail description of requirements and services are created. Construction Operations Building Information Exchange (COBie) published by the UK National Building Specification (NBS) is a non-proprietary data format for the publication of a subset of building information models (BIM) focused on delivering asset data distinct from geometric information. It can also be treated as guidelines for project stakeholders involved in delivering the final model.

Although various standard contract protocols have been developed to facilitate BIM implementation, project participants should be aware that the process of collaboration in a construction project cannot be standardised and neither can BIM because every project has its own characteristics governed by factors such as local building law, project stakeholders' behaviours, and any other external and environmental factors. The standard contract protocols must be tailored carefully to suit the needs of each project.

\subsubsection{Adoption of relational project delivery systems}

Aligned with the BIM implementation in construction projects, the Australian Construction Industry Forum (ACIF, 2014) promotes a project delivery strategy called Project Team Integration (PTI). PTI is a process to facilitate collaboration, promote cooperative behaviour, utilise the insights of all team members, and minimise waste and optimise project outputs through all phases of projects which includes facilities management. PTI principles can be applied to various contractual arrangements. Project partnering is another project delivery system that was created due to the frustration felt towards the moral hazards inherent in traditional contracts (Lahdenperä, 2012). The standard form of contract developed for project partnering PPC 2000 (2000) creates a central hub that for all project participants to contract on the similar terms. The contract aligns project management methods and process based on trust and cooperation. Apart from PTI and project partnering, IPD is one of the procurement systems that is heavily promoted in the USA to integrate the project participants. A standard form of contracts was developed for Integrated Project Delivery (IPD), such as the Standard Multi-Party Integrated Project Delivery (IPD) Agreement (ConsensusDOCS 300, 2007) and the Multi-Party Agreement for Integrated Project Delivery published by the American Institute of Architects (AIA) Doc. C191 (2009). Compared with project partnering, IPD has a more formal decision process, shared liability, a waiver of consequential damages, and gain and pain sharing, which might be optional to limit loss. Both types of relational project delivery systems have common features such as promoting a cooperative culture that leads to good faith and mutual respect, better communication and commitment to improvement (Lahdenperä, 2012).

\subsubsection{Early contractor involvement}

Early contractor involvement is heavily promoted by PTI. This practice supports the designbid-build contractor involved in the design stage in resolving constructability issues. An absence of this practice could lead to an unwarranted dispute. A lawsuit was filed over construction of a life science building (Palos et al., 2013), in which the building services contractor suffered damages due to the designer who used BIM to fit the building services system 
into a ceiling plenum did not notify the contractor that a specific sequence was required for the building services system to fit. Consequently, the contractor brought an action against the employer, the employer then sued the designer, and the designer's insurance carrier joined the engineering firm that designed the building services system. Apparently, if the contractor was involved in the design of the building services with BIM, the dispute could have been avoided.

\subsection{Liabilities}

Three approaches were used to address the issues of liability, namely, (1) the application of economic loss doctrine and common law, (2) the use of governing contracts and (3) liabilities covered by Professional Indemnity Insurance.

\subsubsection{Principles of economic loss doctrine and common law}

In addressing the issue of liabilities, application of the economic loss doctrine is different in the United States and in the United Kingdom. In the United States, if a party would like to sue for pure economic loss, he must have a contract with the defendant (Simonian \& Korman, 2010). Additionally, purely economic losses cannot be recovered through a cause of action in negligence. The economic loss doctrine is specifically addressed in a restatement provision, and parties with the intention to rely jointly on BIM information are usually in an unfavourable position to apply such damage (Ashcraft, 2008). In contrast, in the United Kingdom, the existence of tortious liability for pure economic loss relies on the parties' factual relationship; such liability is not merely based on their "contractor" designation (McAdam, 2010). Thus, the legal liability is based on the extent of participation of team members, although there is no direct contractual relationship.

Addressing the issue of standard of care in both countries is based on the contributions of each party to the use of a model in the BIM contracts. The issues pertaining to standard of care are usually determined by the common law or governing contract (Lowe \& Muncey, 2009).

\subsubsection{Addressed explicitly by contracts}

Liability related to model corruption was addressed by most of the protocols. ConsensusDocs 301 (2008) Clause 5.1 states that "each party shall be responsible for any contribution it makes to a model or that arises from that party's access to that model." Clause 5.8 further grants an extension of time to the party to rectify the error due to the defect in the software and expressly mentions that the grant is only limited to the party who could not avoid any delay or loss by the exercise of reasonable care. Similar to the position of ConsensusDocs 301 (2008), CCP (2013) Clause 10.8 states, "[T]he Contractor shall ensure that there is no potential or actual clash, conflict, discrepancy, omission, error... where it designs a part of the Works ..." Clause 11.3.4 also specifies, "[T]he Contractor who designs the whole of the works shall select and remain responsible for the suitability and integrity of the selected software... or another information extract from any model."

The provision of CIC (2013a) appears to be in conflict with the legal positions of the protocols discussed. CIC (2013a) Clause 5.1 states that the project team members shall not be 
liable for any data corruption except failure to comply with the protocol. Clause 5.2 further specifies, "[T]he Project Team Member shall have no liability to the Employer in connection with any corruption or any unintended amendment, modification or alteration of the electronic data ... save where such corruption, amendment, modification or alteration is a result of the Project Team Member's failure to comply with this Protocol." Although the protocol requires the Project Team Members to adhere to the Information Requirements and Model Production and Delivery Table (MPDT), the Project Team Members accept no liability for the accuracy of the model. This provision is close to the previous practice of liability avoidance, in which the designer's model was marked for "information purposes only". This provision would lead to inefficiency as in the past if the project participants feel the necessity to verify the model integrity in the Common Data Environment (Udom, 2013).

\subsubsection{Professional Indemnity Insurance}

The liabilities encountered by the designers can be insured against. Professional Indemnity Insurance is necessary for the designers in construction projects (Eadie et al., 2014; Bataw, 2013) and for the contractors (Ashcraft, 2008). ConsensusDocs 301 (2008) Clause 5.7 takes a proactive approach by demanding each party to obtain and maintain a minimum value of insurance coverage to cover the party's contributions, incorporate this requirement in the contracts with project participants involved and submit the certificate of insurance to demonstrate the compliance with the requirements. Although there is no explicit requirement in CIC (2013a) to request project participants to procure Professional Indemnity Insurance, CIC (2013b) still provides a best practice guide to indicate what project participants might be required to do so that their professional indemnity insurance arrangements are in order.

\subsection{Model ownership and IPR}

\subsubsection{Model ownership and IPR}

To address the model ownership and IPR issues, most of the protocols specified that the ownership of the model shall be vested in its original contributor. CIC (2013a) Clause 6.2 states that "any rights (including but not limited to any copyright) subsisting in the Material and any proprietary work contained in the Material shall, as the case may be, vest or remain vested in the Project Team Member." If the employer wants to own all Project IPR, then the protocol must be amended in the project participants' agreements. ConsensusDocs 301 (2008) Clause 6.4 specifies that the contract between the employer and the designer shall govern whether the client is entitled to use the full design model. The similar approach applied by AIA E203TM-2013 (2013) Article 2.1 states that the party who transmit the digital data is the copyright owner of the digital data.

To resolve the issue that each model contributor can potentially have concerns with respect to ownership of their repurposed model and data, ConsensusDocs 301 (2008) Clause 6.6 specifies that other project participants who contribute to a model are not the co-authors of the model unless otherwise stated. AIA E203TM-2013 (2013) Article 2.3 also states clearly that the party who transmit the digital data does not transfer any ownership right to generate the digital data. CCP (2013) Clause 10.2.2 applies a similar approach by stating that if the 
contractor proposes the change to the design, the contractor shall retain the copyright and all other intellectual rights to his design unless the contractor waives his rights in the design. Clause 11.3 also states that the copyright of the model of the contractor who designs the whole works shall remain vested in the contractor. However, the solution to the issue of ownership of a model contributor who repurposes the model and data provided by CIC (2013a) remains unclear. Although clause 6.2 emphasises that the copyrights or any rights subsisting in the model shall remain vested in the project team members, it does not state clearly whether the party who repurposed the model and data has any right to these elements.

\subsubsection{Infringement of Another's IPR}

To prevent the claim of infringement of another's IPR, most protocols require project participants to grant a license to other project participants to use and access the model. CIC (2013a) Clause 16.3 requires project team members to grant a license to the employer and other team members to transmit, copy and use the material, whereas ConsensusDocs 301 (2008) Clause 6.2 specifies that the party of contribution shall grant a license to the project participants to use, reproduce and display or distribute for the project only. AIA E203TM-2013 (2013) Article 2.1 stipulates that "the transmission of digital data constitutes a warranty by the Party transmitting digital data to the Party receiving digital data... in accordance with the Authorized Uses of Digital Data established pursuant to the terms of the Exhibit" CCP (2013). Clause 11.1.2 states that if the model is owned by the employer, the employer shall grant a license to use the model to the Contractor. In addition, clauses 6 and 7 emphasise that no liability shall arise from using a model that is licensed.

\subsubsection{Protection of business knowledge}

Various approaches have been adopted by the standard protocols to prevent the model from being reused by non-proprietary owners. ConsensusDocs 301 (2008) Clause 6.6 stipulates that if the project participants wish to use the model for marketing or educational purpose, this use should be clarified in the contract; otherwise, the license is limited to keeping an archival copy. AIA E203TM-2013 (2013) Article 2.2 also provides protections to the model owner by requiring the party who receives the data not reveal it to any person. Article 2.3 further limits the rights of the receiving party to use, modify, or further transmit the file for designing, constructing, using, maintaining, altering or adding to the project consistent with the Exhibit. Moreover, CIC (2013a) Clause 6.5 specifies that the licence granted by the party shall not include the right to change the Material without the written consent of the owner of the data provided that amendment is permitted under the Agreement.

\subsubsection{Protection for a creation that requires hard work}

To protect the hard work of the designers, an information structure coding system of all elements in BIM should be set up by the company involved in the BIM-enabled project. This system is similar to the concept of the BIM Object Element Matrix (OEM). The non-geometric information can express especially in the coding system despite the geometric expression of a BIM element remains universal. The company can declare its copyright ownership and resolve the issues of protecting elements whose creation requires hard work (Fan, 2014). 


\subsubsection{Security and access control}

Prior to BIM implementation, careful consideration should be given to whether the integrity of the electronic data is guaranteed. It is necessary to have a certain level of insurance protection against financial losses due to breaches of data security (Manderson et al., 2015). Moreover, most of the protocols take a proactive approach to ensuring data security and access control. For instance, ConsensusDocs 301 (2008) Clause 3.2.7 requires the Information Manager to run information system scans routinely to maintain model security. AIA E203TM-2013 (2013) Article 4.8.2.8 requires that project participants responsible for managing the model shall facilitate the development and revision of mode management protocols by including model security requirements. CIC (2013a) Appendix 2 requires that security requirements and access rights procedures shall apply to the project procedures. CCP (2013) Clause 11.1.4 stipulates that the model shall be maintained in accordance with the BIM protocol under the direction of the Data Security Manager.

\subsection{Unclear rights and responsibilities}

\subsubsection{Design delegation}

ConsensusDocs 301 (2008) Clause 1.1 stipulates, "[T]he addendum does not effectuate or require a restructuring of contractual relationships or shifting of risks between or among the project participants other than as specifically required per the addendum and the attachments." Apparently, this clause proposed that the use of BIM does not necessitate parties to assume any roles other than their conventional roles. In other words, the architect remains the leading designer in the collaboration platform and remains responsible for the design quality.

In terms of who shall ensure that all deviations are resolved, if the model is checked automatically via a clash detection software, none of the project participants would check the information before it was incorporated into the model. As discussed previously, CIC (2013a) has a different position on other protocols; it mentions that no liability shall arise from issues with model integrity. Other protocols such as ConsensusDocs 301 (2008) and CCP (2013) require project team members to be responsible for maintaining the integrity of the model. The PAS 1192-2 (2013) information management protocol can be treated as a guideline for parties included in the contracts, defining the responsibilities and input-output workflows of project participants.

\subsubsection{Roles of coordinating and maintaining model}

CIC (2013a) Guidance 4 suggests that the information manager function is likely to be performed by either the Design or Project Lead, who could be the consultant or contractor to different stages of the project. This approach is similar to ConsensusDocs 301 (2008); the role of information manager shall likely be performed by the Architect, Engineer or Construction Manager. Both protocols also define the list of roles of the information manager, who shall be responsible for coordinating, updating and maintaining the information model. Both protocols also require the information manager to manage and maintain the model integrity and security in the Common Data Environment or Data Transfer Protocol. However, there 
is a slight difference in the roles assigned in the CCP (2013). CCP (2013) requires that the design coordination manager shall not only coordinate, update and maintain the information model but also be responsible for part of the role in risk management. The responsibilities of managing and maintaining model integrity and security shall rest with the Data Security Manager. Both the Design Coordination Manager and the Data Security Manager shall be appointed by the Employer; if neither is appointed, the responsibilities shall be assigned to the Contract Administrator. If the Contractor designs everything, the responsibility to appoint the design coordination manager and data security manager shall rest with the contractor.

Although the responsibility to update, review and maintain the consistency of the protocol shall rest with the information manager per 3.7 of CIC (2013a) and the design coordination manager in Clause 10.13.2 of CCP (2013), ConsensusDocs 301 Clause 4.1 specifies that these responsibilities should rest with all project participants. Apart from appointing the information manager, CIC (2013a) Clause 3.1.1. requires the employer to create and arrange the protocol, which includes the employer information requirement and Model Production Delivery Table (MPDT) (CIC, 2013a). However, ConsensusDocs 301 (2008) Clause 4.1 requires all project participants to be responsible for creating and arranging the protocol. For CCP (2013), if the contractor contributes to design the whole works, he is responsible for obtaining the employer's confirmation of acceptance of each level of development. He shall also review the elements that link with the model, notify the Contract Administrator of the person in charge of design coordination, create and range the protocol, and archive the asbuilt model (CCP, 2013).

\subsubsection{Auditing models}

Auditing here means to audit the quality performance of the model to ensure model compliance with building codes. For instance, CIC (2013) in the MDPT requires contractors to conduct regulation compliance analysis during the project definition and handover stages. Additionally, apart from complying with building codes, the model shall be audited to ensure that it complies with the timeline or model deliverables required by the employer. CCP (2013) Clause 35.2.1 provides a feasible example by stating that the project time manager shall submit the contractors' design execution plan to the auditor for quality assurance. A management or audit system of all inputs into the BIM model that allocates the responsibilities of the various design consultants, constructors and/or clients is advisable and will assist when addressing liability issues should they arise (Hamdi \& Leite, 2013).

\subsubsection{Additional costs arising from BIM implementation}

Olatunji (2011) contended that an addendum to the professional scales of fees is required and that standard remuneration must be defined for BIM projects. However, there is an opinion that the service of the designer is typically billed at the hourly rate; if BIM eventually makes the design process more efficient, the billable hours will decrease (Arensman \& Ozbek, 2012). Note that one of the main functions of the contract is to safeguard the parties' transaction cost. Transaction cost arises from an economic exchange (Li, Arditi, \& Wang, 2013). An example of the transaction cost is the cost arising from using the BIM, as mentioned previ- 
ously. When a transaction such as the use of BIM becomes more complex and uncertain, parties to the contracts are more likely to enforce a stronger mechanism to safeguard their investments (Parmigiani \& Rivera-Santos, 2011). Hence, it is unsurprising that one of the important legal concerns raised by the authors is who shall pay for the cost of appointing the model manager and any other associated cost. CCP (2013) states that the Design Coordination Manager and Data Security Manager shall be appointed by the Employer. Both CIC (2013a) and ConsensusDocs 301 (2008) also state that the employer and its representative shall appoint the Information Manager. This point implies that the employer shall be responsible for paying the cost of appointing these roles. Concerning who pays the additional cost arising from using BIM, such as the costs of purchasing the BIM software and implementing the BIM, the protocols generally only mention who shall be responsible for appointing the model manager; the payment is required to be paid by the Employer if he would like to use the model of the contributor. Other additional costs shall be paid by the project participants who use BIM in the projects.

\subsubsection{Rights of owners to change the design}

Based on the existing contract practices, it is apparent that clients have the right to change the design. However, if this right is compared with the rights between a website's builder and the employer for whose organisation the website was built, it is possible that the employer has the right to change anything. It is also possible to limit the rights, in which case the owner might only be licensed 'limited use of the website.' A proper contract strategy is required to address such issues (Chao-Duivis, 2011).

\subsubsection{Privity of contract and rights to rely on the accuracy of the models}

In addressing the issue of "privity of contract", the legal solutions provide by the United States and the United Kingdom are different. However, using the collaborative model in both countries reduces the possibility that the defence of using "privity of contract" will be successful. In the United States, the Restatement of Torts (Second) Section 552 defines the requirements for a misrepresentation claim. Therefore, in the context of the design-bid-build, contractors and subcontractors relying on a model from a designer are likely to be able to file an action against the designer for damages caused by negligent errors of the designer as the designer is aware that other parties are relying on the model's accuracy (Ashcraft, 2008). In addition, ConsensusDocs 301 (2008) clarifies its position on the issue of "privity of contract". Clause 1.2 states, "[T]he addendum is not intended to create privity of contract among any project participants beyond that which otherwise exists at law or in the terms of the governing contract." The addendum is not intended to create privity of contract between the designer and the contractor. As discussed previously in the UK legal position of economic loss doctrine, the existence of tortious liability for pure economic loss depends upon the precise factual nature of the relationship between the parties rather than its designation. The key issue that must be addressed in the BIM working platform is the extent to which participation can give rise to legal liability, even when no contractual relationship might exist (McAdam, 2010). Hence, the best practice is to define in the contracts expressly and clearly the models, levels of model detail and accuracy that project participants can rely on. 
Pertaining to the solutions to the issue of rights to rely on the models, the approaches adopted by protocols are different, but they imply a similar meaning - that is, the project participants have rights to rely on the accuracy of the provided models or data only after the agreement or any digital data protocol is formed. AIA E203TM-2013 (2013) Article 3.4.1 states that the party is at his sole risk if he uses the digital data without authorization before the agreement is finalised or any digital data protocols are established. ConsensusDocs 301 (2008) Clause 5.3 specifies that the project participants can rely upon the accuracy of the dimensions provided as defined in the Contributor's Dimensional Accuracy Representation. CCP (2013) Clause 10.5 specifies, “... [when] the Employer has provided the Contractor with any investigation report, data, maps, Drawings, historical records or any other information... it shall have the status identified in the Special Conditions. If no status is stated, such investigation report, data, maps, Drawings, historical records or other information may be relied upon by the Contractor." Nevertheless, the right of project participants to rely on the model stated in CIC (2013a) is rather unclear. CIC (2013a) Guidance 5 states, "[I]t is the responsibility of the Information Manager to agree and issue the Information Requirements, which should be prepared before the Agreements are concluded, as otherwise, the parties will have to rely on the other contractual arrangements, which may not address the items covered by the Information Requirements." There is no provision in the protocols that explicitly mentions which models' accuracy the project participants can rely on or that if the Information Manager failed to prepare the Information Requirements, the parties must rely on the accuracy of information provided by other contract documents.

\subsubsection{Avoidance of responsibility under means and methods}

In the United States, it is advisable that project participants involved in BIM-enabled projects include the BIM contract protocols in their contracts to avoid responsibility under means and methods. In an empirical case study by $\mathrm{Ku}$ and Pollalis (2009), a contractual provision with respect to the use of BIM to provide information to the contractor and subcontractors was incorporated by the architect. The authors also referred to the AIA standard contract to prevent any liability for construction means, methods, techniques, sequences, or procedures. Including the BIM contract protocol assists the architect in using his design model within the limit of conventional design responsibilities.

\subsubsection{Spearin doctrine}

In the United States, although BIM contract protocols such as ConsensusDocs 301 (2008) allocate certain responsibilities among the parties, the legal position of ConsensusDocs 301 on the risk allocation of the parties is clear. The document is not intended to restructure the contractual relationship. Hence, in design-bid-build BIM-enabled projects, the architect remains the person in charge of design, and the owner remains responsible per Spearin for loss or damage that results in insufficient information supplied by the owner, which includes plans and specifications (Lowe \& Muncey, 2009). 


\section{Discussions and conclusions}

Common legal issues fall into four categories, namely, (1) incompatibility of procurement systems with BIM; (2) there is an increasing liability for design errors, transition errors, loss of data or data misuse; (3) model ownership and IPR; and (4) unclear rights and responsibilities of project participants.

The findings revealed that most of the legal issues faced in both the United States and the United Kingdom are similar except for certain issues such as those pertaining to avoidance of responsibility in means and methods - and the Spearin doctrine is not applicable in the United Kingdom legal context. Although both countries also experienced the issue of "privity of contract", the application of the economic loss principle to recover damages for the suffering party due to using the collaborative model was rather different in each country.

It is important to note that other regions may also have different legal positions in this regard. For instance, in the Northern Europe, the Dutch law in the Netherlands on intellectual property specifies that the maker of a design is the owner of it. There is a need to differentiate whether the shared models of project participants belong to "communal work" where the contributions cannot be the subject of an independent judgement or "combination of works" where an independent judgement of the contributions is possible. If the shared model is the "communal work", consent from all other model creators should be obtained. However, if the shared model is the "combination works", an express agreement is required as the law, in this case, is not mandatory. In the Netherlands, the liability position pertaining to the design error is contrasted with the Spearin doctrine in the USA. Liabilities lie not on the party who contributed to the idea leading to damages but it lies with the party who accepted the idea and use his specific knowledge to perform the tasks (Chao-Duivis, 2011).

Apart from the design-bid-build method, the incompatibility of procurement systems, copyright issues, liability and unclear rights and responsibilities are also applied to other traditional procurement methods such as the design and build, construction management and management contracting methods. As BIM impacts the conventional ways of collaboration among project participants, the discussed legal issues will also bring legal consequences to these traditional procurement methods subjects to the existing roles of project participants in the contract structures. If BIM is applied to relational project delivery systems such as project partnering, project alliances and IPD, the incompatibility of procurement systems are no longer an issue to the projects. The liability and unclear roles and responsibilities issues should not be seen as the hindrance to project operation due to the cooperation elements have been existed in these procurement systems such as the early involvement of key parties, transparent financials, shared risk and reward, joint decision-making, and a collaborative multiparty agreement that are typically incorporated in the contractual arrangements to a varying degree (Lahdenperä, 2012). Nevertheless, as formal contracts are the safeguard mechanism that used by project participants in securing their transactions, it is suggested that project participants who work in any project delivery system should examine the potential legal consequences associated with the use of BIM and stipulate the terms and conditions of how parties work together in coordinating BIM deliverables in formal contracts to prevent unwanted disputes. 
The study has several implications. From the perspective of contract drafting, the legal issues and the discussed solutions provide general guidelines for practitioners to select the best option that is appropriate for them to incorporate in their project delivery systems and contracts, which should lead to greater BIM adoption and effective use of BIM. The paper also contributes to conflict management prior to BIM implementation by providing various solutions to the legal issues discussed. The paper fundamentally contributes to the development of knowledge in BIM-based contract administration because it not only establishes knowledge on what is currently applied in the industry but also, more importantly, provides significant insights to practitioners and future researchers on the existing gap found in the findings.

None of the procurement systems is perfect in the eyes of the project stakeholders. However, as is evident in the empirical case studies by Sebastian (2011), despite the protocols indicating that BIM should be defined at the beginning of a project, the use of the design-bidbuild method still has its own weaknesses. For example, designers and contractors continue to work within the ambit of their traditional responsibilities without committing to satisfying the needs of end users, which is important in delivering sustainability to a hospital. It is true, therefore, that relational contracting is considered appropriate in applying BIM effectively to deliver project outcomes. Relational contracting such as the IPD project, delivered by most of the project key players engaging in a single contract, with remuneration based on costplus expenses and profit only earned if the project was delivered at less than an agreed target cost, can resolve the issue of "privity of contract" (McAdam, 2010). However, the design-bidbuild contract delivery method continues to be used in the majority of BIM-enabled projects (Pandey et al., 2016). Thus, early contractor involvement does not mean that the designers are obliged to share their model with the contractor unless express contract provisions to that effect are included in the contracts. However, most clients remain afraid that they might not be able to transfer risk that emerges later in the construction phase as the information is built up in the early contractor appointment (Mosey, 2009). Given the limitations of these alternative approaches to the design-bid-build procurement, a more innovative project delivery system without altering the original orientation of the design-bid-build structure is required so that it can be widely accepted by the industry to deliver BIM effectively. Future research might investigate approaches for improving the trust among contracting parties in the design-bid-build system, because trust is one of the essential elements that promotes collaboration among parties and thereby enhances project performance.

The result of the study also reveals that the standard of care for the designers and other project participants can be altered due to additional contractual responsibilities loaded on the project participants. With respect to the liability issues, the approaches adopted by the protocols in addressing the issue pertaining to the liability for model integrity are different. On the one hand, ConsensusDocs 301 (2008) and CCP (2013) state that the model contributor shall be responsible for model integrity. ConsensusDocs 301 (2008) even provides a provision to grant an extension of time to project participants to address errors that did not result from their defaults. On the other hand, CIC (2013a) specifies that project participants shall accept no liability for the model integrity that does not result from non-compliance with the protocol. Both approaches have their limitations. It is unfair for project participants to be liable for the model and data, which are out of their control. Moreover, if the project 
participants accept no liability for the model integrity, the practice of delivering BIM effectively will become less effective because project participants accept no liability for model accuracy. Further investigation is required to evaluate which approaches can bring the best project outcome. Future research is also required to examine the potential for alteration of the standard of care to reinforce the confidence of the construction industry in addressing the legal issues arising from using BIM. It is also evident that some improvements are required in the existing protocols, such as outlining the roles of the relevant party in auditing the model to ensure compliance with the building regulations and employer's requirements from the beginning of the project until project completion. This role is significant and should be provided in the protocols to ensure that project participants deliver the model according to the requirements, particularly during the handover stage, so that the employer can use the model for facility management. Current protocols focus on allocating responsibility to the information manager for ensuring the security of the model and data. However, the protocols should also spell out the minimum model and data security requirements.

Certain limitations must be considered because some of the related publications might not be retrievable. In addition, the review of the legal issues and their solutions is based on the literature identified from the fifty-five (55) conference papers and journal articles based on certain keywords and databases as highlighted in the review methodology, standard BIM contract protocols and other relevant literature sources. It is possible that this study has overlooked certain legal issues and solutions that might also be suitable for inclusion in the papers. Thus, the classification of legal issues can vary depending on the individual perspective. At present, a considerable amount of time is required to ensure that a virtual model and its associated data are transferred without error. The best contract practices could be achieved if the interfacing issues are resolved and the project participants are willing to accept the legal implications arising from the adoption of BIM.

\section{References}

Abdirad, H. (2015). Advancing in Building Information Modeling (BIM) contracting: trends in the AEC/ FM Industry. In Proceedings of the AEI Conference 2015. Milwaukee, Wisconsin. https://doi.org/10.1061/9780784479070.001

Ahn, Y. H., Kwak, Y. H., \& Suk, S. J. (2015). Contractors' transformation strategies for adopting building information modeling. Journal of Management in Engineering, 32(1), 05015005. https://doi.org/10.1061/(ASCE)ME.1943-5479.0000390

AIA Document E203TM-2013. (2013). Building information modelling and digital data exhibit. Published by The American Institute of Architects, United States.

Alreshidi, E., Mourshed, M., \& Rezgui, Y. (2017). Factors for effective BIM governance. Journal of Building Engineering, 10, 89-101. https://doi.org/10.1016/j.jobe.2017.02.006

Al-Shammari, M. A. (2014). An appraisal of the protocol that was published by the construction industry council (CIC) to facilitate the use of building information modelling (BIM) on projects. In Proceedings 30th Annual ARCOM Conference (pp. 623-632). Portsmouth, UK.

Arensman, D. B., \& Ozbek, M. E. (2012). Building information modelling and potential legal issues. International Journal of Construction Education and Research, 8, 146-156. https://doi.org/10.1080/15578771.2011.617808

Ashcraft, H. (2008). Building information modeling: a framework for collaboration. Construction Lawyer, 28(3), 1-14. 
Australian Construction Industry Forum (ACIF). (2014). A framework for the adoption of project team integration and building information modelling. Paper presented at Strategic Forum for the Australasian Building and Construction Industry. Australian Procurement and Construction Council, Australia.

Azhar, S., Nadeem, A., Mok, Y. N. J., \& Leung, H. Y. B. (2008). Building Information Modelling (BIM): a new paradigm for Visual interactive modelling and simulation for construction projects. In Proceedings of the First International Conference on Construction in Developing Countries "Advancing and Integrating Construction Education, Research and Practice" (pp. 435-446). Karachi, Pakistan.

Bataw, A. (2013). Making BIM a realistic paradigm rather than just another fad. In ARCOM Doctoral Workshop (pp. 11-21). Birmingham City University, UK.

Bosch-Sijtsema, P., Isaksson, A., Lennartsson, M., \& Linderoth, H. C. (2017). Barriers and facilitators for BIM use among Swedish medium-sized contractors - "We wait until someone tells us to use it". Visualization in engineering, 5(3). https://doi.org/10.1186/s40327-017-0040-7

C191. (2009). Standard form multi-party agreement for integrated project delivery. The American Institute of Architects, USA.

Chao-Duivis, M. A. B. (2011). Some legal aspects of BIM in establishing collaborative relationship. International Construction Law Review, 28(3), 264-275.

Chew, A., \& Riley, M. (2013). What is going on with BIM? The Way to 6D. The International Construction Law Review, 53-265.

Chong, H. Y., Fan, S. L., Sutrisna, M., Hsieh, S. H., \& Tsai, C. M. (2017). Preliminary contractual framework for BIM-Enabled projects. Journal of Construction Engineering and Management, 143(7), 04017025. https://doi.org/10.1061/(ASCE)CO.1943-7862.0001278

CIC. (2013a). CIC BIM Protocol. Construction Industry Council, United Kingdom.

CIC. (2013b). Best practice guide for professional indemnity insurance when using building information models. Construction Industry Council, United Kingdom.

ConsensusDocs 300. (2007). Standard Multi-Party Integrated Project Delivery (IPD) Agreement. ConsensusDocs, United States.

ConsensusDocs 301. (2008). Building Information Modelling (BIM) Addendum. ConsensusDocs, United States.

CCP. (2013). Contract for complex projects. Chartered Institute of Building, United Kingdom.

Davies, K., Davies, K., McMeel, D. J., McMeel, D. J., Wilkinson, S., \& Wilkinson, S. (2017). Making friends with Frankenstein: hybrid practice in BIM. Engineering, Construction and Architectural Management, 24(1), 78-93. https://doi.org/10.1108/ECAM-04-2015-0061

Eadie, R., Odeyinka, H., Browne, M., McKeown, C., Odeyinka, H., \& McNiff, S. (2013). BIM implementation throughout the UK construction project lifecycle: an analysis. Automation in Construction, 36, 145-151. https://doi.org/10.1016/j.autcon.2013.09.001

Eadie, R., Odeyinka, H., Browne, M., McKeown, C., \& Yohanis, M. (2014). Building information modelling adoption: an analysis of the barriers to implementation. Journal of Engineering and Architecture, 2(1), 77-101.

Elhag, T., \& Al-Sharifi, M. (2014). The viability of BIM for UK contractors. Paper presented at Proceedings of the International Conference on Construction in a Changing World. Heritance Kandalama, Sri Lanka.

Elmualim, A., \& Gilder, J. (2013). BIM: Innovation in Design Management, influence and challenges of implementation. Architectural Engineering and Design Management, 10(34), 183-199.

Enegbuma, W. I., Ologbo, A. C., Aliagha, U. G., \& Ali, K. N. (2014). Preliminary study impact of building information modelling use in Malaysia. In IFIP International Conference on Product Lifecycle Management (pp. 51-62). Springer Berlin Heidelberg.

Enegbuma, W. I., \& Ali, K. N. (2011). A preliminary critical success factor Analysis of Building Information Modelling (BIM) implementation in Malaysia. Paper presented a Proceedings of the Asian Conference on Real Estate (ACRE 2011): Sustainable Growth, Management Challenges. Thistle Johor Bahru, Malaysia. 
Fan, S. L. (2014). Intellectual property rights in building information modelling application in Taiwan. Journal of Construction Engineering Management, 140(3), 04013058, 1-6. https://doi.org/10.1061/(ASCE)CO.1943-7862.0000808

Fenice Investments Inc. v Jerram Falkus Construction. (2009). EWHC 3272 (TCC).

Foster, L. L. (2008). Legal issues and risks associated with building information modelling technology (Master thesis). University of Kansas, the United States.

Ghaffarianhoseini, A., Tookey, J., Ghaffarianhoseini, A., Naismith, N., Azhar, S., Efimova, O., \& Raahemifar, K. (2017). Building Information Modelling (BIM) uptake: clear benefits, understanding its implementation, risks and challenges. Renewable and Sustainable Energy Reviews, 75, 1046-1053. https://doi.org/10.1016/j.rser.2016.11.083

Grant, M. J., \& Booth, A. (2009). A typology of reviews: an analysis of 14 review types and associated methodologies. Health Information \& Libraries Journal, 26(2), 91-108.

https://doi.org/10.1111/j.1471-1842.2009.00848.x

Greenwood, D., Lewis, S., \& Lockley, S. (2010). Contractual issues in the total use of Building information modelling. Proceeding: W113 - Special Track 18th CIB World Building Congress. Salford, United Kingdom.

Gu, N., Singh, V., London, K., Brankovic, L. L., \& Taylor, C. (2008). Adopting Building Information Modeling (BIM) as collaboration platform in the design industry. Paper presented at Proceedings of the 13th Conference on Computer Aided Architectural Design Research. Asia, Chiang Mai, Thailand.

$\mathrm{Gu}$, N., London, K. (2010). Understanding and facilitating BIM adoption in the AEC industry. Automation in Construction, 19, 988-999. https://doi.org/10.1016/j.autcon.2010.09.002

Hamdi, O., \& Leite, F. (2013). Conflicting side of building information modeling implementation in the construction industry. Journal of Legal Affairs and Dispute Resolution in Engineering and Construction, 6(3), 03013004. https://doi.org/10.1061/(ASCE)LA.1943-4170.0000137

Haynes, D. (2009). Reflections on some legal and contractual implications of building information modeling (BIM). Construction Watch, 2(9), 1-9.

Holzer, D. (2007). Are you talking to me? Why BIM alone is not the answer? Paper presented at International Conference on Association of Architecture Schools Australasia. School of Architecture, University of Technology, Sidney, Australia.

Hossain, M. K., Munns, A., \& Rahman, M. M. (2013). Enhancing team integration in Building Information Modelling (BIM) projects. Paper presented at ARCOM Doctoral Workshop on BIM Management and Interoperability. Birmingham, UK.

Hsieh, T. Y., Yeh, F., \& Hsu, K. M. (2012). Legal risks incurred under the application of BIM in Taiwan. 14th International Conference on Computing in Civil and Building Engineering. Moscow, Russia.

Hsu, K. M., Hsieh, T. Y., \& Chen, J. H. (2015). Legal risks incurred under the application of BIM in Taiwan. Proceedings of the Institution of Civil Engineers-Forensic Engineering, 168(3), 127-133. https://doi.org/10.1680/feng.14.00005

Jones, B. (2014). Integrated project delivery (IPD) for maximizing design and construction considerations regarding sustainability. Procedia Engineering, 95, 528-538. https://doi.org/10.1016/j.proeng.2014.12.214

Joyce, R., \& Houghton, D. (2014). Briefing: building information modelling and the law. Proceedings of the Institution of Civil Engineers Management, Procurement and Law, 167(3), 114-116. https://doi.org/10.1680/mpal.14.00012

Ku, K. H., \& Taiebat, M. (2011). BIM experiences and expectations: the constructors' perspective. International Journal of Construction Education and Research, 7(3), 175-197. https://doi.org/10.1080/15578771.2010.544155

Ku, K., \& Pollalis, S. N. (2009). Contractual standards for enhanced geometry control in model-based collaboration. Journal of Information Technology in Construction, 14, 366-384. 
Kuiper, I., \& Holzer, D. (2013). Rethinking the contractual context for Building Information Modelling (BIM) in the Australian built environment industry. Australasian Journal of Construction Economics and Building, 13(4), 1-17. https://doi.org/10.5130/ajceb.v13i4.3630

Kurul, E., Abanda, H., Tah, J., \& Cheung, F. (2013). Rethinking the build process for BIM adoption. Paper presented at CIB World Building Congress. Brisbane, Australia.

Lahdenperä, P. (2012). Making sense of the multi-party contractual arrangements of project partnering, project alliancing and integrated project delivery. Construction Management and Economics, 30(1), 57-79. https://doi.org/10.1080/01446193.2011.648947

Laishram, B. (2013). Building Information Modeling in public private partnership projects - perspectives and hurdles. Paper presented at International Conference on Structural Engineering Construction and Management. Kandy, Sri Lanka.

Larson, D. A., \& Golden, K. A. (2007). Entering the brave new world: an introduction to contracting for BIM. William Mitchell Law Review, 34(1), 75-108.

Lee, J. D., Wang, Y. H., Lin, C. W., Lin, H. H. (2013). Information value of patent litigation and industry competition in Taiwan. Technological and Economic Development of Economy 19(4), 593-605. https://doi.org/10.3846/20294913.2013.837109

Li, H., Arditi, D., \& Wang, Z. (2013). Factors that affect transaction costs in construction projects. Journal of Construction Engineering and Management, 139(1), 60-68. https://doi.org/10.1061/(ASCE)CO.1943-7862.0000573

Liu, Y., Van Nederveen, S., \& Hertogh, M. (2017). Understanding effects of BIM on collaborative design and construction: an empirical study in China. International Journal of Project Management, 35(4), 686-698. https://doi.org/10.1016/j.ijproman.2016.06.007

Lowe, R. H., \& Muncey, J. M. (2009). The ConsensusDOCS 301 BIM Addendum. Construction Lawyer, 29(1), 1-9.

Mahamadu, A. M., Mahdjoubi, L., \& Booth, C. (2013). Challenges to BIM-Cloud integration: implication of security issues on secure collaboration. IEEE International Conference on Cloud Computing Technology and Science, 2, 209-214.

Manderson, A., Jefferies, \& Brwer, G. (2015). Building Information Modelling and standardised construction contracts: a content analysis of the GC21 contract. Construction Economics and Building, 15(3), 72-84. https://doi.org/10.5130/AJCEB.v15i3.4608

McAdam, B. (2010). Building Information Modelling: the UK legal context. International Journal of Law in the Built Environment, 2(3), 246-259. https://doi.org/10.1108/17561451011087337

Mehran, D. (2016). Exploring the adoption of BIM in the UAE construction industry for AEC firms. Procedia Engineering, 145, 1110-1118. https://doi.org/10.1016/j.proeng.2016.04.144

Moher, D., Liberati, A., Tetzlaff, J., Altman, D. G., \& Prisma Group. (2009). Preferred reporting items for systematic reviews and meta-analyses: the PRISMA statement. PLoS med, 6(7), e1000097. https://doi.org/10.1371/journal.pmed.1000097

Mordue, S., Swaddle, P., \& Philp, D. (2015). BIM for Dummie. West Sussex, UK: John Wiley \& Sons.

Mosey, D. (2009). Early contractor involvement in building procurement: contracts, partnering and project management. UK: John Wiley \& Sons. https://doi.org/10.1002/9781444309867

Ngo, M. H. (2012). UK construction industry's responses to government construction strategy BIM deadline and applications to civil engineering education. Paper presened at First Civil and Environmental Engineering Student Conference. Imperial College London, UK.

Olatunji, O. A. (2011). A preliminary review on the legal implications of BIM and model ownership. Journal of Information Technology in Construction, 16, 687-696.

Olatunji, O. A. (2014). Views on Building Information Modelling, procurement and contract management. Proceedings of the Institution of Civil Engineers. Management, Procurement and Law, 167(3), 117-126. https://doi.org/10.1680/mpal.13.00011 
Palos, S., Kiviniemi, A., \& Kuusisto, J. (2013). Future perspectives on product data management in building information modeling. Construction Innovation, 14(1), 52-68. https://doi.org/10.1108/CI-12-2011-0080

Pandey, A., Shahbodaghlou, F., \& Burger, J. (2016). Legal and contractual challenges of Building Information Modeling - designers' perspectives. In Construction Research Congress (pp. 519-527). American Society of Civil Engineers.

Parmigiani, A., \& Rivera-Santos, M. (2011). Clearing a path through the forest: a meta-review of inter organizational relationships. Journal of Management, 37(4), 1108-1136. https://doi.org/10.1177/0149206311407507

PAS1192-2. (2013). Specification for information management for the capital/delivery phase of construction projects using building information modelling. BSI Standards Limited 2013, London, the UK.

PPC 2000. (2000). Standard form of contract for project partnering. Association of Consultant Architects and Association for Consultancy and Engineering, UK.

Redmond, A., Hore, A., \& West, R. (2010). Developing a Cloud integrated life cycle costing analysis model through BIM. Paper presented at CIB W78 2011: Computer Knowledge Building. Sophia Antipolis, France.

Rogers, J., Chong, H. Y., Preece, C. (2015). Adoption of building information modelling technology (BIM) perspectives from Malaysian engineering consulting services firms. Engineering, Construction and Architectural Management, 22(4), 424-445. https://doi.org/10.1108/ECAM-05-2014-0067

Sankaran, B., O’Brien, W. J., Goodrum, P. M., Khwaja, N., Leite, F. L., \& Johnson, J. (2016). Civil integrated management for highway infrastructure: case studies and lessons learned. Transportation Research Record: Journal of the Transportation Research Board, 2573, 10-17. https://doi.org/10.3141/2573-02

Sebastian, R. (2010). Breaking through business and legal barriers of open collaborative processes based on Building Information Modelling (BIM). Paper presented at Proceeding: W113 - Special Track 18th CIB World Building Congress. Salford, UK.

Sebastian, R. (2011). Changing roles of the clients, architects and contractors through BIM. Engineering, Construction and Architectural Management, 18(2), 176-187. https://doi.org/10.1108/09699981111111148

Simonian, L., \& Korman, T. (2010). Legal considerations in the United States associated with Building information modeling. The Construction, Building and Real Estate Research Conference of the Royal Institution of Chartered Surveyors, RICS COBRA. Dauphine Université Paris, France.

Smith, P. (2014). BIM Implementation-Global Strategies. Creative Construction Conference, Procedia Engineering, 85, 482-492. https://doi.org/10.1016/j.proeng.2014.10.575

Sun, C., Jiang, S., Skibniewski, M. J., Man, Q., \& Shen, L. (2017). A literature review of the factors limiting the application of BIM in the construction industry. Technological and Economic Development of Economy, 23(5), 1-14. https://doi.org/10.3846/20294913.2015.1087071

Udom, K. (2013). The CIC BIM Protocol - a critical analysis. NBS. Retrieved from https://www.thenbs. com/knowledge/the-cic-bim-protocol-a-critical-analysis

Walasek, D., \& Barszcz, A. (2017). Analysis of the adoption rate of Building Information Modeling [BIM] and its Return on Investment [ROI]. Procedia Engineering, 172, 1227-1234. https://doi.org/10.1016/j.proeng.2017.02.144

Wang, G. B., Duan, X. R., \& Lei, W. (2011). Research on some critical problems of contracting for Building Information Model. Consumer Electronics, Communications and Networks (CECNet), Xianning University, China.

Yaakob, M., Wan, W. N. A., \& Radzuan, K. (2016). Critical success factors to implementing Building Information Modeling in Malaysia construction industry. International Review of Management and Marketing, 6(8S), 252-256. 